

\title{
Cavity Investigation by Surface Wave Tomography and Microgravity
}

\author{
Adnand Bitri, Kevin Samyn, Thomas Jacob
}

\section{To cite this version:}

Adnand Bitri, Kevin Samyn, Thomas Jacob. Cavity Investigation by Surface Wave Tomography and Microgravity. EAGE Near Surface Geoscience 2014, Sep 2014, Athènes, Greece. 4 p. hal-01025240

\section{HAL Id: hal-01025240 https: / hal-brgm.archives-ouvertes.fr/hal-01025240}

Submitted on 17 Jul 2014

HAL is a multi-disciplinary open access archive for the deposit and dissemination of scientific research documents, whether they are published or not. The documents may come from teaching and research institutions in France or abroad, or from public or private research centers.
L'archive ouverte pluridisciplinaire HAL, est destinée au dépôt et à la diffusion de documents scientifiques de niveau recherche, publiés ou non, émanant des établissements d'enseignement et de recherche français ou étrangers, des laboratoires publics ou privés. 


\section{Introduction}

Shallow cavities, such as karstic caves in carbonate bedrock and near-surface underground mine workings and tunnels, constitute serious hazards for persons and existing constructions due to the risk of collapse and subsidence involving damages to buildings and increased urban development costs. Detection of karstic features, voids, surficial dissolution, fissuring, alteration and unconsolidated material, is thus a major challenge for geophysical methods.

Density and resistivity are known to be good indicators of the alteration and fissuring of draining or saturated epikarst, and electric behaviour may be amplified by the presence of shallow groundwater and strong water circulation. Ground penetrating radar (GPR) can be also suitable where soils or argillaceous cover, that absorbs radar waves, are absent or highly discontinuous.

Recent investigations have reported good results for cavity imaging using surface seismic methods (Samyn et al., 2013, Leparoux et al., 2000; Vogelaar, 2001, Gucunski et al., 1996; Park et al. 1996). Surface wave have several properties that make them useful for near surface characterization. They are usually the largest amplitude waves generated by a surface impact, and their dispersive property allows for quantification of shear wave velocity with depth.

Based on the relative advantages and disadvantages of the different geophysical techniques the most prudent imaging approach is the use of two or more complementary techniques. For example, the exploration of a karst network in the Swiss Jura was conducted by combining GPR which provides a precise image of the most surficial voids and structures, with gravimetry which is sensitive to the presence of deeper and larger heterogeneities (Beres et al., 2001). Debeglia et al. (2006) proposed microgravity and Multi-channel Analysis of Surface Waves (MASW) coupling to detect and characterise karst structure in an urban environment.

This study evaluates the potential of using surface wave tomography (Long, L.T., and Kocaoglu, A.H., 1999, Abbott et al. 2006) with microgravity to image complex near surface cavities. The study area is located in Souzay-Champigny, France, and consists of an abandoned underground quarry network in cretaceous chalky limestone. The cavities are accessible and were partly mapped. The study focuses on the largest mapped cavity.

\section{Data acquisition and processing}

Gravity measurements at Souzay-Champigny site, France, were conducted using two Scintrex CG-5 relative gravimeters. A total of 462 gravity stations were measured, over $80 \mathrm{~m}$ by $82 \mathrm{~m}$ area using 4 by 4 meter grid, and the stations were tied to a local base station that was repeated at an interval of approximately one hour, to estimate and minimise instrumental drift correction. Station elevation was acquired by direct levelling with centimetre accuracy and sensor height was measured to allow gravity reduction to ground level. To obtain the Bouguer anomaly, readings were corrected for instrumental drift, earth tides, elevation, latitude, and terrain effects using BRGM proprietary software. The uncertainty of Bouguer anomaly estimation mainly depends on the errors in the gravity readings. About $20 \%$ of the stations were reoccupied during the survey in order to evaluate the repeatability of gravity measurements. The repeat measurements are in the range of 0 to $15 \mu \mathrm{Gal}$, with $68 \%$ of the repeats being lower than $7 \mu$ gals. Taking into account levelling and terrain correction errors, the combined standard uncertainty on Bouguer anomaly is estimated at $8 \mu \mathrm{Gal}$.

Seismic acquisition geometry consisted of 6 parallels lines with 10m spacing. Each line consists of 24 $10 \mathrm{~Hz}$ single component vertical geophone at $5 \mathrm{~m}$ intervals. Two 48 channels Stratavizor and two 24 channels Geodes from Geometrics were used to record and vertically stack four impacts from $10 \mathrm{~kg}$ hammer. Data were recorded at a sample rate of $0.5 \mathrm{msec}$ during 1 second. As shown in the figure 2a, the raw traces show clear developed surface waves.

The first step in surface wave tomography is to estimate group travel time for each source geophone pair at regular frequency interval. The S-transform was used to identify the arrival times of the surface waves at selected frequencies. The S-transform (Stockwell, et al. 1996) is a time-frequency transform 
which provides a time depended distribution of the signal. It is very similar to the Gabor transform which utilize a Gaussian for spectral localization. The difference is in the S- transform the Gaussian window is scalable with frequency which enhances a better time-frequency resolution. The selected frequencies were limited by the energy in the recorded traces and by their wavelength. In this study reliable energy was observed for frequencies from 13 to $40 \mathrm{~Hz}$. Figure $2 \mathrm{~b}$ shows the results of $\mathrm{S}$ transform for frequencies of $10 \mathrm{~Hz}$. The measured traveltimes for all receivers in the Rayleigh wave fundamental mode time window at a given frequency are used in a tomographic inversion algorithm to reconstruct a 2-D tomogram of group velocity (figure 3). The inversion for each frequency is done separately. Our algorithm uses the finite difference method to calculate travel time to every point on a slowness grid, and solves the inverse problem using a least-squares scheme (Grandjean and Sage, 2004). The core program is mainly based on two algorithms, respectively dedicated to the traveltime computation and to the velocity model reconstruction. A second-order Fast Marching Method (FMM) is used to solve the Eikonal equation over a highly discretized numerical grid, therefore enabling a fast and robust computation of seismic traveltimes between sources and receivers. Wavepaths are computed using 3D Fresnel volumes that enter in the regularization strategy and ensure a good convergence. This approach accounts for complex velocity models and has the advantage of considering the effects of the wave frequency in the velocity model resolution (Husen and Kissling, 2001). The velocity model reconstruction is based on a simultaneous iterative reconstruction technique (SIRT).

\section{Results}

We remove a planar regional trend to the Bouguer anomaly to obtain the residual Bouguer anomaly, in which strong negative anomalies associated to the underground quarry are evident (see Fig 1a). The amplitude of the anomalies reaches some $-0.090 \mathrm{mGals}$ at most. As expected, there is a strong spatial correlation between the shape of the residual gravity anomaly and that of the mapped cavities. Note that the cavity has not been mapped in its entirety, as shown by the large negative gravity anomaly to the North, associated to an unmapped part of the quarry (Fig 1).

In figure 3, we plot the group velocity map for the $10 \mathrm{~Hz}$ frequency. On the plot, we presented also the layout experiment, the negative residual Bouguer anomaly and a part of the mapped quarry. The group velocity ranges from 150 to $450 \mathrm{~m} / \mathrm{s}$. The study area included a cavity structure whose roof is located at the depth of 8 to $10 \mathrm{~m}$. Significant low velocities anomalies in the center of the plot are probably due to the propagation perturbation of surface wave in the presence of cavities. These anomalies overlap well with gravity anomalies and the part of mapped carry.

\section{Conclusions}

Microgravity and surface wave tomography coupling is a promising approach for the detection near surface cavities in an urban environment, the two methods being complementary in depth of investigation and origin of detected anomalies. Microgravity, conducted with low spacing and careful implementation in order to ensure high resolution and accuracy, remains, one of the methods most suited to the detection of voids, even relatively small, in the first $20 \mathrm{~m}$ of depth. Its weakness lies in its ambiguities of interpretation. Surface wave tomography which is sensible to the soil stiffness, contributes at reducing these ambiguities, by characterising the mechanical behaviour of the gravity anomalous zones, and finally at minimising the volumes and costs of mechanical controls. 


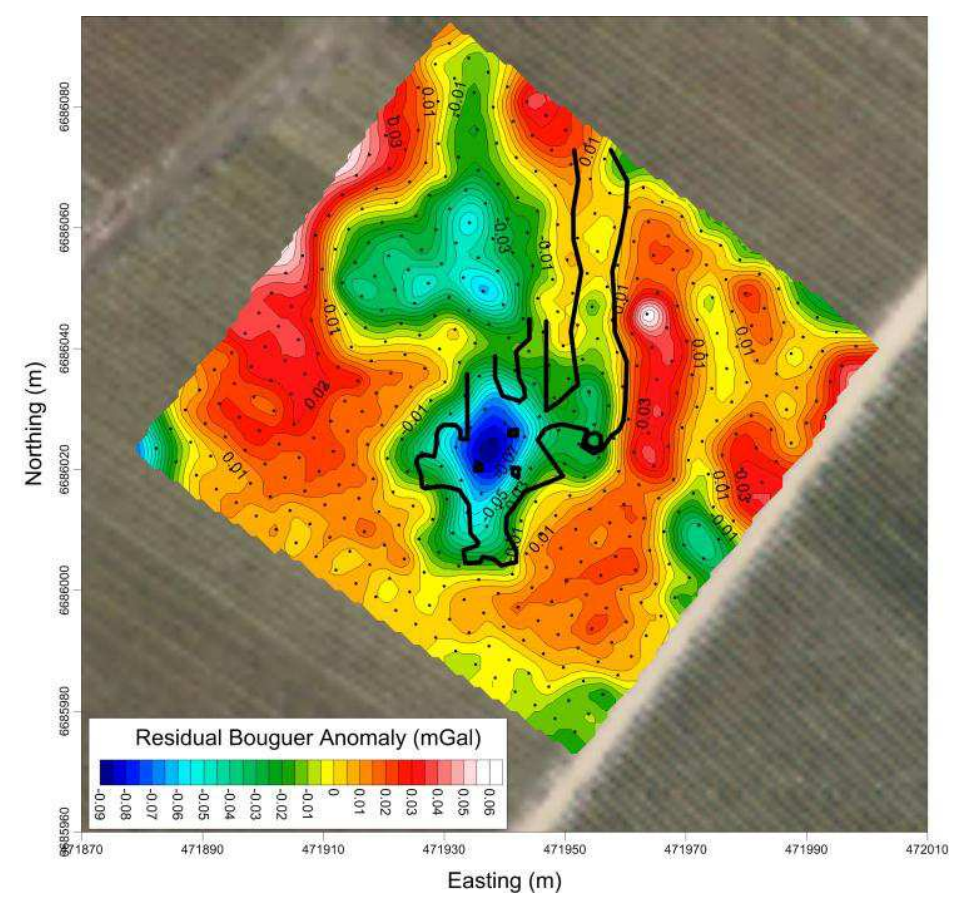

Fig. 1- a- residual Bouguer anomaly, the thick black lines denote the mapped cavity limits
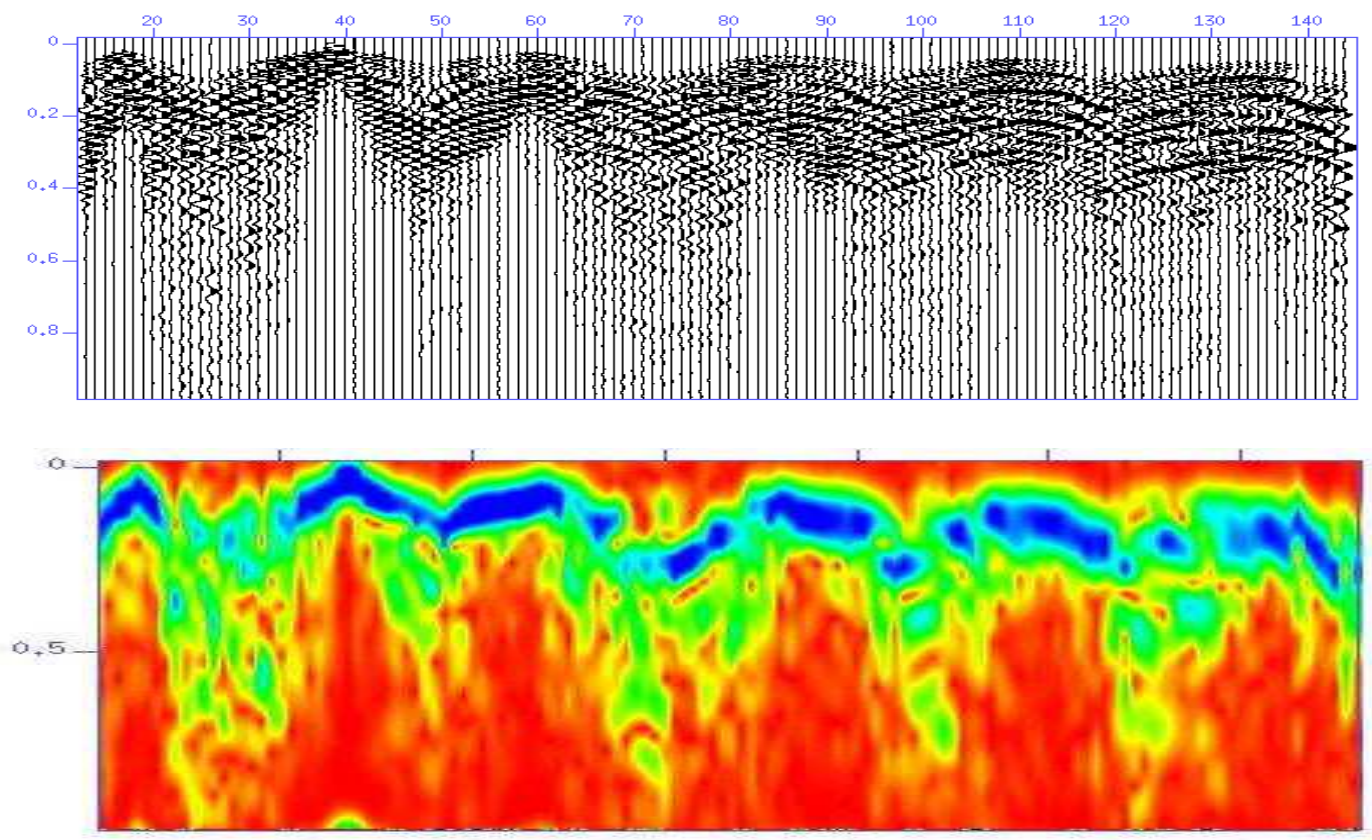

Fig. 2- a- 3D raw shot gather $\mathbf{b}$ - S-transform for the $10 \mathrm{~Hz}$ frequency. 


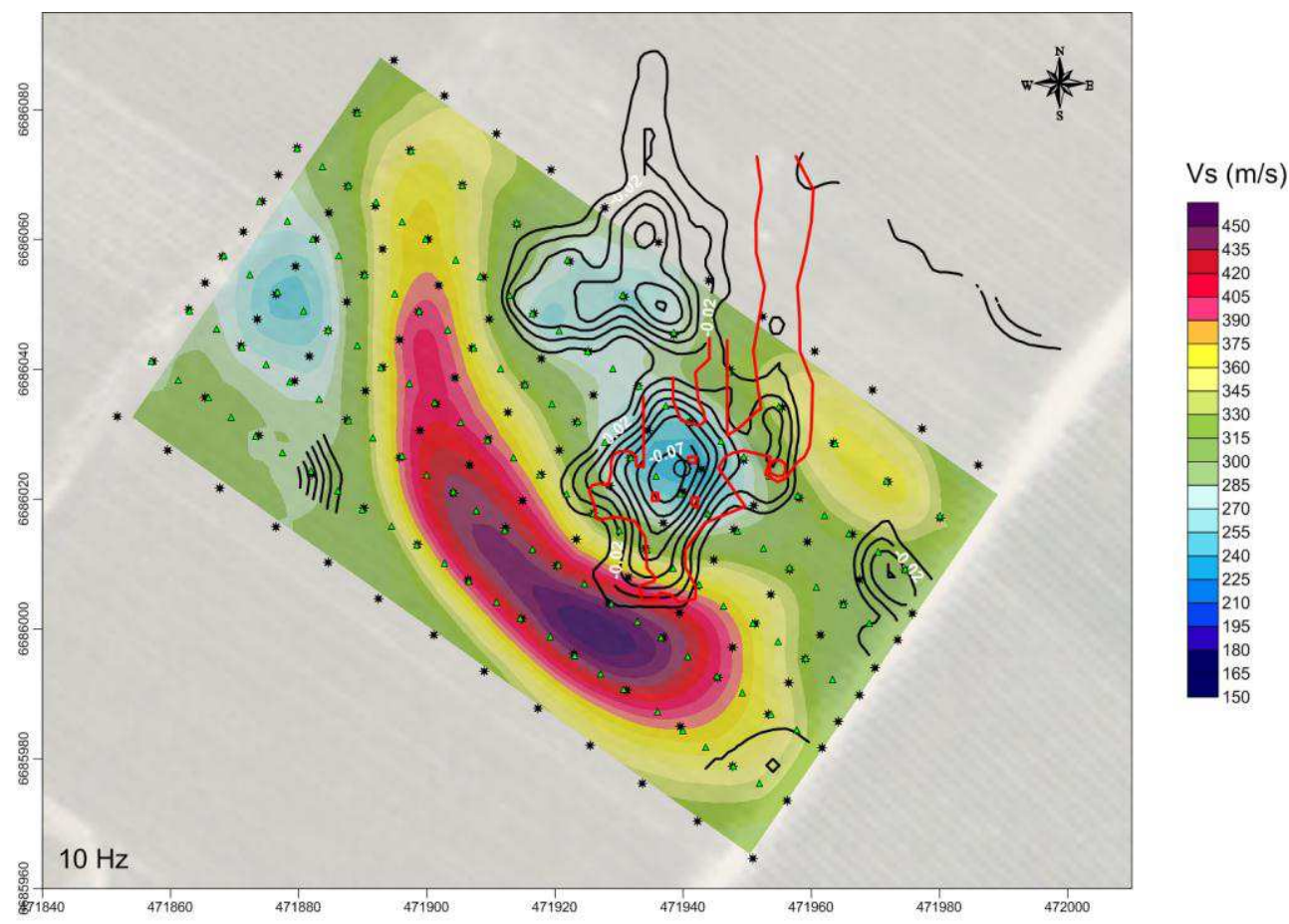

Fig. 3. Group velocity map for frequency $10 \mathrm{~Hz}$ with layout experiment.

\section{References}

Abbot, R.E., Bartel, L.C, Engler, B.P., and Pullammanappallil, S., 2006. Surface wave and refraction tomography at the FACT Site, Sandia National Laboratories, Technical Report SAND20065098

Beres, M., Luetscher, M., Olivier, R., 2001. Integration of ground-penetrating radar and microgravimetric methods to map shallow caves. Journal of applied geophysics, 46, 249-262.

Debeglia, N. and Dupont, F., 2002. Some critical factors for engineering and environmental microgravity investigations. Journal of applied geophysics, 50, 435-454.

Debeglia, N., Bitri, A., and Thierry, P., 2006. Karst investigations using microgravity and MASW;Application to Orléans, France. Near Surface Geophysics 2, 215-225

Grandjean, G., Sage, S., 2004. JaTS: a fully portable seismic tomography software based on Fresnel wavepaths and a probabilistic reconstruction approach. Computers and Geosciences 30, 925935.

Husen, S., Kissling, E., 2001. Local earthquake tomography between rays and waves: fast ray tomography. Physics of the Earth and Planetary Interiors 123, 129-149.

Long, L. T. and Kocaoglu, A. H. 1999. Surface-Wave Group-Velocity Tomography for Shallow Structures. Proceedings of the Symposium on the Application of Geophysics to Engineering and Environmental Problems - SAGEEP '99, Oakland, California, March 14-18, EEGS, 85-94.

Leparoux D., Bitri A., Grandjean G., 2000. Underground cavity detections: a new method based on seismic Rayleigh waves. European Journal of Environmental and Engineering Geophysics, 5, 33-53.

Park, C.B., Xia, J. and Miller, R.D., 1998. Ground roll as a tool to image near-surface anomaly. Expanded Abstr. $68^{\text {th }}$ Ann. Internat. SEG Mtg., New Orleans: 874-877

Rybakov, M., Goldshmidt, V., Fleischer, L. and Rotstein, Y., 2001. Cave detection and 4-D monitoring: a microgravity case history near the Dead Sea, The Leading Edge, 20, 8:896-900

Samyn, K., Bitri, A., Grandjean, G. 2013. Imaging a near-surface feature using crosscorrelation analysis of multi-channel surface wave data, Near Surface Geophysics, 11, 1-10.

Stockwell, R.G., Mansinha, L., and Lowe, R.P., 1996 Localization of the complex spectrum: The S transform: IEEE Trans. Signal Process., 44, No 4, 2957-2962 